\title{
Students' Satisfaction and Factors in Using Mobile Learning among College Students in Kuwait
}

\author{
Ahmad Sulaiman ${ }^{1 *}$, Ali Dashti ${ }^{2}$ \\ ${ }^{1}$ Kuwait University College of Education, Kuwait, KUWAIT \\ ${ }^{2}$ Gulf University for Science and Technology, Kuwait, KUWAIT
}

Received 26 September 2017 - Revised 19 April 2018 - Accepted 21 April 2018

\begin{abstract}
Mobile learning (ML) technology and its services have provided a new platform for higher education institutions to enhance the learning process. Mobile learning provides learners with flexibility and ubiquity. However, students' satisfaction and factors of using ML in private and public universities remain academically unexplored. In this study, the constructivism learning theory was applied to investigate students' satisfaction and the factors that predict the use of $M L$ among public and private university students in the learning process. The researchers developed a questionnaire with 43 items to gather information about the degree of students' satisfaction and factors in using mobile learning among college students for both public and private universities in Kuwait. A sample of 1,012 undergraduate students were randomly selected from three different universities in Kuwait. The study was conducted in the second semester of 2015/2016. The results showed that females were more likely to be satisfied with smartphones for educational purposes than males and that Kuwaiti students tend to be more satisfied with smartphones for educational purposes than non-Kuwaiti students. Factors used to predict students' satisfaction with $\mathrm{ML}$ were Internet speed, smartphone portability, smartphone skills, screen size, gender, nationality, and college. The researchers suggest expanding the current study to include graduate students.
\end{abstract}

Keywords: Kuwait, learning satisfaction, Mobile learning (ML), smartphones, college students

\section{MOBILE LEARNING IN HIGHER EDUCATION INSTITUTIONS IN KUWAIT}

There has been a considerable increase in the use of mobile devices such as smartphones all over the world (Astin, 1993; Ichikawa, Chipchase, \& Grignani, 2005; Liaw, 2008; Wali, Winters, \& Oliver, 2008). By the end of 2018, an estimated 1.4 billion smartphones will be in use, according to a new study by ABI research (Leonard, 2013), and with a world population of 7 billion, this means one smartphone for every five people. This increase in the number of smartphone devices has steered researchers to focus on using such devices as a tool to support teaching and the learning process (Koszalka \& Ntloedibe-Kuswani, 2010). According to Ichikawa et al. (2005), the three things that people most frequently carry are keys, wallets, and phones. In this work, the researchers study the importance of smartphones for students for academic purposes. McQuiggan, Kosturko, McQuiggan, and Sabourin (2015) quoted Franklin Delano Roosevelt who stated that "we cannot always build the future for our youth, but we can build our youth for the future" (p.1). Mobile technology offers features that enable it to break the educational system wide open, involving students in new ways and making educational experiences more profound, if higher educational institutions can effectively utilized structured, integrated approaches for implementations of mobile technology (McQuiggan et al., 2015). Smartphones have changed many aspects of our lives, especially education. Wang, Shen, Novak, and Pan (2009) have stressed the importance of interactivity between and among students and teachers. They state that many online classes simply provide recorded lectures, which only reinforces the negative effects of passive, non-participatory learning. In their study, which involved a blended English classroom of 1,000 students

(C) 2018 by the authors; licensee Modestum Ltd., UK. This article is an open access article distributed under the terms and conditions of the Creative Commons Attribution License (http://creativecommons.org/licenses/by/4.0/). $\square$ a.sas@ku.edu.kw (Correspondence) $\square$ dashti.a@gust.edu.kw 


\title{
Contribution of this paper to the literature
}

- The findings of the present study help faculty members to reconsider their teaching style and adopt ML to keep pace with technological developments.

- The results of current study help decision makers in higher education institutions to engage ML into educational process in effective manner.

- The results of the current study enhance the research field of educational technology by exploring the factors (technical and demographics) that best predict the level of satisfaction among undergraduate students who use ML.

(800 being online), they showed that ML activities enhanced students' engagement in the classrooms and switched students from being passive learners to being truly engaged learners who are behaviorally, intellectually, and emotionally involved in their learning tasks. According to the American Distance Education Consortium (ADEC), student satisfaction "is the most important key to continue learning" (para. 5) (Bolliger \& Wasilik, 2009). Student satisfaction is defined as a student's perceived value of his or her educational experiences at an educational institution (Astin, 1993) or how comfortable the user feels with the educational systems to achieve his or her goals (Alqahtani \& Mohammad, 2015). In the field of human-technology interaction, Alqahtani and Mohammad (2015) reported that user satisfaction refers to the feelings of affection experienced by interacting with the system; consequently, satisfaction is a subjective set of interactive experiences influenced by effective elements. Successful implementation of ML is frequently measured by students' satisfaction (Sachs \& Hale, 2003). Several components influence student satisfaction in an ML environment. The instructor, technology, and interactivity are the three key factors that affect students' satisfaction when using smartphones in ML (Bolliger, 2004). Additional factors that affect satisfaction are communication with course constituents and management systems used. Moreover, students' perceptions of tasks' value and self-efficacy, social ability, quality of systems, and multimedia instruction have been identified as critical components (Liaw, 2008). In the next section, the researchers discuss the definitions of smartphones (SP) as a critical factor for mobile learning.

\section{DEFINITIONS OF SMARTPHONES (SP)}

To define smartphones (SP), it is crucial to understand the definitions of mobile learning (ML). Many studies define ML differently based on their interests. Early definitions of ML focused on technological tools; later, the focus shifted to mobility, where the learning as well as the acquisition of knowledge and skills is not restricted to a fixed place or time. Recently, performance has become important in ML. "Performance" refers to any activity that allows an individual to be more productive when consuming, interacting, or creating information using a mobile device (Driscoll \& Van Barneveld, 2015). Moses (2008) defines ML as a form of e-learning that involves the use of a mobile device, such as a smartphone, to produce learning experiences anywhere and anytime to meet the needs of different learners. By contrast, Peng, Su, Chou, and Tsai (2009) use Hummel and Hlavacs' definition of ML:

\begin{abstract}
"A situation in which a multitude of connected and embedded systems and devices work together to build an ambient computing allows people both to access learning content from anywhere at any time, and to communicate with colleagues or lecturers synchronously and asynchronously much more frequent" (p.6).
\end{abstract}

Peng et al. (2009) interpreted ML as "widespread" and extending beyond the simple notion of "anytime, anywhere learning" to also include learning "the right thing" at "the right time" at "the right place". The Oxford English Dictionary defines a smartphone as "any of various telephones enhanced with computer technology." The term "smartphone" later came to refer to a phone "typically with a touch-screen interface and Internet access" (Brenner, 2013).

Dikkers (2012) defines mobile learning as including instant and active connection to online information to promote personal growth and increased communication within professions and communities. Thus, immediate access to information would satisfy students, which will positively be reflected in their learning process. In this study, the researchers will use this definition to explain how access to information enhances students' satisfaction.

Smartphones typically include cell-phone features in addition to other features that are popular in other mobile devices, such as personal digital assistants, media players, and GPS navigation units. Most smartphones have a touchscreen interface, a camera, high-speed cellular data connectivity, and motion sensors, in addition to various application programs. Mobile operating systems include Android, IOS, Firefox, Sailfish, Tizan, Ubuntu Touch, BlackBerry, Symbian, Windows Mobile, Balm OS, and Bada. Applications (or "apps") are software programs designed to run on smartphones. Most mobile service providers in Kuwait offer 4G+ and LTE-Advanced connections delivering high-speed data communication. 4G LTE is an abbreviation for the fourth-generation long- 
term evolution of the wireless communication standard used for high-speed data for mobile phones and data terminals (Brenner, 2013; Peng et al., 2009). In the next section, the researchers discuss the constructivism theory and its implications for ML.

\section{CONSTRUCTIVISM THEORY}

The concept of constructivism is that learning is an active process in which learners construct new ideas according to their current and past knowledge (Bruner, 1966). Constructivism is a very broad theory, and it has several aspects, such as radical, social, physical, evolutionary, postmodernist, information-processing, and cybernetic (Murphy, 1997). This study focuses on the social interaction part, since ML provides excellent interaction with the environment. As knowledge continues to raise, access to what is needed is more critical than what the learner currently seizes. Social constructivism presents a model of learning that acknowledges the tectonic shifts in society where learning is no longer an internal, individualistic activity (Siemens, 2005). Siemens wondered how students' functioning is altered when new tools such as ML are utilized. Siemens also added that constructivism provides insight into the learning skills and tasks needed for learners to grow in a digital era. Constructivism focuses on creating a learning environment that centers learners in constructing the meaning of what they are learning and socially negotiating that meaning with peers. In constructivist theory, learning should be designed so as to be authentic, relevant, immersive, and contextual, where learners are actively involved in the learning process and are supported by instructors with scaffolding and metacognitive cues (Driscoll \& Van Barneveld, 2015, p. 9).

Bruner (1966) states that both the teacher and the student should engage in an active dialogue to translate information to be learned into a format appropriate to the learner's current state of understanding. One major characteristic of the constructivism learning theory is that motivation and satisfaction are key components in learning (Hein, 1991); thus, constructivists argue that individuals' motivations and satisfaction greatly affect their abilities to learn. The most basic motivation for and satisfaction of learning is an individual's desire to make sense of the world (Hein, 1991).

Sawang, Newton, and Jamieson (2013) tested three areas of e-learning and their impact on learners' satisfaction: (1) levels of technological efficiency, (2) authenticity and complexity and (3) organizational support. The results supported previous hypotheses and suggested that certain learners' characteristics and e-learning characteristics, such as authenticity, significantly contributed to learners' satisfaction with e-learning. Furthermore, the results supported the fact that learners are more satisfied when e-learning includes authentic activities, which is congruent with the constructivist learning theory.

Several studies discuss how constructivism can be adapted to new technologies such as ML. Bada (2015) suggests that teaching with new technology can promote students' active construction of an internal representation of knowledge by interacting with the information to be learned. Lunenburg (2011) says that teachers should engage students with contradicting hypotheses and then encourage discussion. Due to its ability to provide rapid interaction and feedback, ML is very well suited to keep students engaged in discussions.

Technology and tools such as ML provide opportunities for students to explore a variety of attitudes so they can construct their own knowledge of various concepts (Rice \& Wilson, 1999). Such tools have shifted the focus from "knowledge-as-possession" to "knowledge-as-construction" and from "outside-guided" learning to "selfguided" learning (Rice \& Wilson, 1999, p. 6). Such a shift, implied in ML, is compatible with constructivism's learning principles. Constructivism and technology tools have reshaped the conception of learning challenges and brought new learning possibilities for almost all teaching and learning situations, including the mobile learning environment. Mobile learning brings new opportunities and improves student-teacher communication (Al-Fahad, 2009).

\section{The objectives of the study can be stated as follows:}

(1) Measure both public and private university students' degree of satisfaction with using smartphones in the learning process in the State of Kuwait.

(2) Investigate any differences in satisfaction based on students' gender, nationality, grade point average (GPA), and college attended for both public and private universities.

(3) Explore the factors, both technical and demographic, that best predict the satisfaction among students who use ML.

The importance of the study findings can be summarized as follows:

- Help decision makers in higher education institutions to effectively incorporate ML into the educational process.

- Entice faculty members to reconsider their teaching style and adopt ML to keep pace with technological developments. 
- Contribute to the employment of educational mobile devices in higher education.

- Bridge the gap between theory and practice.

Problem of the study:

Since the students' satisfaction and factors of using ML in private and public universities remain academically unexplored, the study addressed the following questions:

Q1: What is the difference in student satisfaction with the use of ML between public and private universities in the State of Kuwait?

Q2: Are there any differences in satisfaction based on students' gender, nationality (Kuwaiti and non-Kuwaiti), GPAs, and college attended for both public and private universities?

Q3: What are the factors, both technical and demographic, that best predict the level of satisfaction among students that use ML?

\section{RESEARCH METHODOLOGY}

The researchers followed a descriptive approach, which is appropriate for the nature of this study. To answer the research questions, a questionnaire was designed to gather information about students' satisfaction with using SPs in the learning process in both public and private universities in the State of Kuwait. The researchers requested 15 undergraduate volunteers from Kuwait University (KU) and 15 undergraduate volunteers from both the Gulf University for Science and Technology (GUST) and the American University of Kuwait (AUK) to distribute the questionnaire among students in all three universities and colleges of the current study. The questionnaire was divided into three sections. The first section asks 10 questions related to the student's background information. The second section of the survey asks students 23 questions about their satisfaction with using SPs in their learning process. The last section includes 10 more questions regarding learning and technology in general.

The analysis was performed using SPSS version 22 for Windows and utilizing Cronbach's alpha to test the internal consistency of the instrument. Further, ANOVA and t-tests were conducted to measure inferential statistics between independent and dependent variables. Finally, linear regression analysis was performed to understand the relationship between the variables. The researchers conducted a pilot study to test the questionnaire in a small portion of the population of KU, GUST and AUK students before collecting the actual data. To ensure the validity of the questionnaire, the researchers sent it to a group of arbitrators composed of faculty members to examine and determine the extent of its powers in achieving the goals of the research study.

\section{SAMPLE OF THE STUDY}

The original sample of this study was 1200 undergraduate students, who were randomly selected from among 38,200 undergraduate students from three universities. To ensure that every participant had a chance of selection for this study, the randomization was scheduled on two different days of lectures (Monday-Wednesday where the length of the lecture is 75 minutes and Sunday, Tuesday and Thursday where the length of the lecture is 50 minutes). The sample represented three universities: 31,000 students from KU, 5,100 students from GUST and 2,100 students from AUK. There were 614 female participants, representing $61 \%$ of the sample, and 398 male students. The representations of the study were reasonable because the number of female students is greater than the number of male students. The sample of the current study represented all colleges in the three universities (College of Law, College of Arts, College of Science, College of Medicine, College of Engineering and Petroleum, College of Allied Health Science, College of Education, College of Sharia and Islamic Studies, College of Business Administration, College of Pharmacy, College of Dentistry, College of Life Sciences, College of Social Sciences, College of Architecture, College of Computing Sciences and Engineering, and College of Public Health). The following section discusses the results of the present research study.

\section{RESULTS AND DISCUSSION}

The questionnaire was distributed among students at three public and private universities, for a total of 1200 undergraduate students. One hundred eighty-eight questionnaires were excluded due to redundant answers for all questions or because of failure to answer $95 \%$ of the questions. The majority (876) of the respondents were Kuwaiti nationals; 122 were non-Kuwaitis. Of the three universities, one was public (Kuwait University, n=550) and two were private (Gulf University for Science \& Technology, n=174, and American University of Kuwait, $\mathrm{n}=289$ ). Most of the students were 18 to 23 years of age $(84 \%)$. Of the 1,012 students (398 male and 614 female) surveyed, 1,008 own smartphones; $70 \%(n=708)$ use their smartphone more than 4 hours daily, $24 \%(n=239)$ spend two to four hours daily, and only $6 \%(n=61)$ use it for an hour or less daily. Most students have access to the Internet using either $3 \mathrm{G}$ or $4 \mathrm{G}$ mobile-carrier networks, while others use campus Wi-Fi. Participants who use 3G represent 
Table 1. Items Related to Smartphone Satisfaction

1 Using a smartphone helps me find new ways of learning at the university

2 I feel satisfied using a smartphone in my university's studies

3 A smartphone gives me flexibility to use it any time

4 I interact more with students when using a smartphone

5 Using a smartphone increases my interaction with my teacher in comparison with old methods

6 Using a smartphone increases my interaction with my university's studies in comparison with old methods

7 Learning through a smartphone is an effective interactive tool in the learning process

8 Using a smartphone in my university's studies saves me time

9 Using a smartphone in my university's studies saves me effort

10 I feel enthusiastic using a smartphone in my university's studies

11 I am satisfied with the content of the message when using the smartphone because it is concise and useful

${ }_{12}$ Using a smartphone in my university's studies provides me the chance to get the information faster from other tools, 12 including the computer

13 A smartphone helps me do my homework faster than other tools, including the computer

14 Using a smartphone in my university's studies increases my educational efficiency

15 Using a smartphone in my university's studies increases my educational achievement

16 Using a smartphone in my university's studies makes the learning process easier

17 I don't feel comfortable when using the smartphone in my university's studies

18 I can use a smartphone in my university's studies independently, without the need of others

19 I can use a smartphone in my university's studies in groups (like WhatsApp)

$20 \mathrm{My}$ instructor encourages me to use a smartphone in my classes

$21 \mathrm{I}$ recommend to my friends that they use a smartphone in their university's studies

22 I learn more when using a smartphone in my university's studies

23 I will take more courses in the future that depend on a smartphone

$46.4 \%(n=470)$ of the sample, whereas those who use $4 \mathrm{G}$ totaled $21 \%(\mathrm{n}=210)$. The remaining $27 \%$ use university $\mathrm{Wi}-\mathrm{Fi}(\mathrm{n}=270)$, and only a small number $(4 \%)$ have a separate mobile Wi-Fi router $(n=35)$ to connect to the Internet.

For the test of the students' satisfaction with using a smartphone, the reliability for the 23 items related to the smartphone satisfaction is $a=.928$, while the mean for the 23 items among the three universities was close, with $\mathrm{M}=3.83$ and $\mathrm{SD}=.63383$.

To answer Q1, a one-way between-subjects ANOVA was conducted to compare any significant differences in students' satisfaction between the three universities, and the result showed that there was no such difference at $\mathrm{p}<.05[\mathrm{~F}(2,1010)=.894, \mathrm{p}=0.409]$.

To answer Q2, dealing with the satisfaction among male and female students, a t-test showed that there was a significant difference based on gender $\mathrm{t}(1009)=-3.449, \mathrm{p}=.001$. Male students $(\mathrm{M}=3.75, \mathrm{SD}=.65)$ were less likely to be satisfied than female students $(M=3.90, S D=.61)$ when smartphones are used for educational purposes. The researchers believe that this outcome is due to cultural differences. Females tend to be more satisfied with ML than males because they perceive it as a means to freely express their thoughts and ideas and be more involved in discussion without any restrictions. Females look at ML as being a tool to exchange ideas. This result contradicts that of Tan, Ooi, Sim, and Phusavat (2012), which stated that the gender factor did not significantly affect the usage of mobile learning. However, this study is compatible with the results of Sarigöz (2016), where it was shown that female students had heightened perceptions of and were more satisfied with ML than male students. Another study conducted by (Alfailakawi, 2004) that tested the use of ML for Kuwait University students showed that female students were found to be more serious about using ML than male students.

For differences in students' satisfaction based on nationality, the t-test results showed that there was a significant indication that Kuwaiti students $(\mathrm{M}=3.85, \mathrm{SD}=.62)$ are more satisfied than non-Kuwaiti students $(\mathrm{M}=3.68, \mathrm{SD}=.72)$ in regard to satisfaction with $\mathrm{ML} t(996)=2.96, \mathrm{p}=.003$. The researchers believe that Non-Kuwaiti students may prefer and adopt a more traditional method of learning, while Kuwaitis tend to accept new methods of learning due to their wide exposure to technology and availability of sophisticated phones.

For satisfaction based on students' GPAs, a one-way between-subjects ANOVA analysis showed a significant difference $[\mathrm{F}(3,971)=3, \mathrm{p}=.030]$ in this aspect. Students with GPAs higher than 3 out of $4(\mathrm{M}=3.75, \mathrm{SD}=.65)$ are more likely to be satisfied than those with GPAs between 2 and $2.49(\mathrm{M}=3.91, \mathrm{SD}=.57)$. This could be attributed to the fact that students with higher GPAs are more eager and motivated to learn new methods of learning to gain knowledge than those with lower GPAs. Similarly, a one-way between-subjects ANOVA analysis was also conducted to analyze the impact of colleges on student satisfaction. The results revealed that there were significant differences between colleges at the $\mathrm{p}<.05$ level $[\mathrm{F}(12,900)=2.739, \mathrm{p}=.001]$. Pharmacy and Religious Studies colleges were less satisfied with ML, with $\mathrm{m}=3.6$, whereas the colleges with the highest satisfaction were colleges 
Table 2. M-learning Satisfaction Among Colleges

\begin{tabular}{lccc}
\hline \multirow{2}{*}{ College } & $\mathbf{N}$ & $\mathbf{1}$ & $\mathbf{2}$ \\
\cline { 2 - 4 } & $\mathbf{N}$ & 3.5911 & 3.6181 \\
\hline Pharmacy & 14 & 3.6181 & 3.6800 \\
\hline Religious Sharia & 47 & 3.6800 & 3.6872 \\
\hline Others & 82 & 3.6872 & 3.7167 \\
\hline Engineering and Petrol & 67 & 3.7167 & 3.8456 \\
\hline Social & 48 & 3.8456 & 3.8527 \\
\hline Science & 92 & 3.8527 & 3.8733 \\
\hline Law & 35 & 3.8733 & 3.9048 \\
\hline Business Administration & 242 & 3.9048 & 3.9236 \\
\hline Artical & 79 & 3.9236 & 3.9634 \\
\hline Medical Assistant & 85 & 3.9634 & 3.9952 \\
\hline Life Sciences & 24 & 3.9952 & 4.0445 \\
\hline Education & 22 & & .088
\end{tabular}

Table 3. Factors Affecting Students' Satisfaction

\begin{tabular}{llccc}
\hline & Statements & $\mathbf{N}$ & Mean & Std. Deviation \\
\hline 1 & Ease of carrying the smartphone helped me to use it in my studies & 1010 & 4.295 & 0.78266 \\
\hline 2 & I have the skills to use the smartphone & 1005 & 4.054 & 0.89992 \\
\hline 3 & Internet charges won't stop me from using a smartphone in my studies & 1006 & 4.052 & 0.96264 \\
\hline 4 & Internet speed is sufficient to use a smartphone in my studies & 1006 & 3.949 & 1.06064 \\
\hline 5 & I face problems when charging my smartphone on campus & 1007 & 3.693 & 1.21217 \\
\hline 6 & Wi-Fi is available on all campuses & 1004 & 3.653 & 1.28314 \\
\hline 7 & The small screen on the smartphone won't prevent me from using it in my studies & 1009 & 3.599 & 1.15575 \\
\hline 8 & Wi-Fi signal is strong & 1009 & 3.464 & 1.27434 \\
\hline 9 & I feel disappointed when I use a smartphone due to technical problems & 1009 & 3.028 & 1.22686 \\
\hline 10 & Due to passwords, I face problems connecting to the Wi-Fi & 1011 & 2.972 & 1.37128 \\
\hline
\end{tabular}

of Education and Life Sciences, with $\mathrm{m}=4.0$ (see Table 2). The researchers believe that religious people tend to be more cautious in using mobile learning and hesitate to try new ways of learning, such as adopting ML, as a part of their personal learning and development. The researchers also believe that students from the College of Sharia may not be exposed to heavy use of ML in their teaching style. Since the College of Sharia teaches Islamic and religion studies, the respondents are less likely to adopt ML. This finding supports the results of the study entitled "Kuwait University students use mobile learning," which concluded that students who majored in Islamic studies and in the College of Sharia were less satisfied with ML than were students in other colleges (Alfailakawi, 2004).

The ANOVA test revealed that there was a significant difference between groups' time spent on their smartphones and their satisfaction $([\mathrm{F}(2,1400)=10.00, \mathrm{p}=.001]$. Students who spent more than 4 hours $(\mathrm{M}=3.89$; $\mathrm{SD}=.61)$ per day on their smartphones were more satisfied than those who spent one hour or less daily $(\mathrm{M}=3.65$; $\mathrm{SD}=.71)$ or those who spent between $2-4$ hours daily $(\mathrm{M}=3.71 ; \mathrm{SD}=.66)$.

The mean and the standard deviation for the effect of technology on students' satisfaction showed that ease of carrying a smartphone $(M=4.29, S D=0.78)$ is the leading factor for using ML, while students' skill came second $(M=4.05, S D=.899)$ (see Table 3$)$.

To answer Q3, regarding the technical and demographical impact in predicting the level of satisfaction among students who use ML, a linear regression analysis was performed using satisfaction as the dependent variable. Various technical aspects were entered as the first block of independent variables, such as connection speed and cost, smartphone portability, smartphone technical problems, smartphone skills, smartphone screen size, battery charging on campus, Wi-Fi availability on campus, Wi-Fi signal power on campus, and password problems on campus. In the second block, other independent variables related to demographics were entered, such as gender, nationality, age, years in school, GPA, university, colleges, and time spent using a smartphone. The regression analysis revealed that the first set of the technology variables had significant impact $\left(\mathrm{R}^{2}\right.$ change $=.428, \mathrm{~F}$ change $(816,10)=61.130, p=.001)$. Of the technical variables, Internet speed $(\beta=.095, p=.002)$, smartphone portability $(\beta$ $=.402, \mathrm{p}=.001)$, smartphone skills $(\beta=.196, \mathrm{p}=.001)$, screen size $(\beta=.134, \mathrm{p}=.001)$, and password problems on campus $(\beta=.134, \mathrm{p}=.001)$ were the main predictors of smartphone ML satisfaction. Research in this field has classified these outcomes as external conditions or environmental factors that can facilitate satisfaction (Hassanein \& Wang, 2010). 
Table 4. Linear Regression Analysis of Predictors of Smartphone Satisfaction with M-Learning

\begin{tabular}{|c|c|c|}
\hline Predictors & Regressions 1 & Regressions 2 \\
\hline Internet speed & $.095^{\star *}$ & $.095^{\star \star}$ \\
\hline Portable & $.402^{\star \star \star}$ & $.391^{\star \star *}$ \\
\hline Internet cost & .012 & .000 \\
\hline Technical problems & -.005 & -.020 \\
\hline Skills & $.196^{\star \star \star}$ & $.202^{\star \star \star}$ \\
\hline Screen size & $.134^{\star \star \star}$ & $.130^{\star \star \star}$ \\
\hline Battery charging on campus & .036 & .039 \\
\hline Wi-Fi availability on campus & .008 & .021 \\
\hline Wi-Fi signal power & .031 & .030 \\
\hline Password problems on campus & .134 & $.128^{\star \star \star}$ \\
\hline Gender & & $.067^{*}$ \\
\hline Nationality & & $-.074^{\star *}$ \\
\hline Age & & -.011 \\
\hline School year & & .034 \\
\hline GPA & & -.044 \\
\hline University & & -.029 \\
\hline College & & $-.62^{*}$ \\
\hline Time spent using smartphone & & $.053^{*}$ \\
\hline$R^{2}$ & .428 & .450 \\
\hline Adjusted $\mathrm{R}^{2}$ & .421 & .438 \\
\hline $\mathrm{R}^{2}$ Change & .428 & $.022^{*}$ \\
\hline
\end{tabular}

A second regression analysis including the second set of variables also revealed a significant impact level ( $R^{2}$ change $=.450, \mathrm{~F}$ change $(808,8)=3.979, \mathrm{p}=.001)$. All of the first set of variables, which were technical variables, including Internet speed $(\beta=.095, \mathrm{p}=.002)$, smartphone portability $(\beta=.391, \mathrm{p}=.001)$, smartphone skills $(\beta=.202$, $\mathrm{p}=.001)$, screen size $(\beta=.130, \mathrm{p}=.001)$, and password problems on campus $(\beta=.128, \mathrm{p}=.001)$, remained as predictors even after being controlled by the second set of predictors. Furthermore, the results showed that gender $(\beta=.67, p=.018)$, nationality $(\beta=-.074, p=.007)$, college $(\beta=-.062, p=.025)$ and time spent using a smartphone $(\beta$ $=.053, \mathrm{p}=.047$ ) were additional predictors of smartphone satisfaction (see Table 4).

As a result, this study shows that Internet speed, smartphone portability, smartphone skills, screen size, password problems on campus, gender, nationality, type of college, and time spent using a smartphone are the main predictors of satisfaction with the use of smartphones in ML (see Table 4).

\section{CONCLUSION AND FUTURE RECOMMENDATIONS}

In conclusion, this study showed that students in public and private universities were satisfied using SPs in learning. The results revealed that female students were more satisfied with ML than male students. Moreover, Kuwaiti students were more satisfied than non-Kuwaitis. Further, students with high GPAs were more satisfied with ML than students with lower GPAs. In addition, students from Education and Life Science colleges were more satisfied with ML as compared to students from all other colleges, and the least satisfied students were from the colleges of Pharmacy and Religious Studies. It was found that students who spent more than four hours daily using SPs were more satisfied with ML than students who spent less time on their SPs. Finally, the study found that the factors that best predict level of satisfaction with smartphone-based ML were Internet speed, smartphone portability, smartphone skills, screen size, password problems on campus, gender, nationality, college type, and time spent using a smartphone. One implication of the current study based on constructivism theory is for educators to create lessons in which the students, not the teacher, are constructing meaning. Another implication is that male students should be motivated to use SP in their learning by creating a stimulating environment.

There are some limitations to the study that should be highlighted. The current study was limited to college students attending KU (which is a public university), and two private universities that are AUK and GUST. In addition, the study was conducted during spring semester of 2015/2016, and only undergraduate students from both gender were involved in the study.

For future research, we suggest expanding the current study to include graduate students in order to make the data more reliable. The researchers propose that policy makers should focus on and prepare appropriate infrastructure for ML in higher education institutes. Policy makers could officially set criteria and implement ML in higher education institutes in Kuwait for teaching and learning by taking the above factors into consideration. 


\section{ACKNOWLEDGEMENTS}

Our gratitude goes to Kuwait University for funding this research project.

\section{REFERENCES}

Al-Fahad, F. N. (2009). Students' attitudes and perceptions towards the effectiveness of mobile learning in King Saud University, Saudi Arabia. Turkish Online Journal of Educational Technology, 8, 10.

Alfailakawi, Y. (2004). Kuwait university students use mobile learning. Arab Journal of Human Sciences, 22, 163.

Alqahtani, M., \& Mohammad, H. (2015). Mobile applications' impact on student performance and satisfaction. Turkish Online Journal of Educational Technology, 14, 102-112.

Astin, A. W. (1993). What matters in college: Four critical years revisited (Vol. 1). San Francisco, CA: Jossey-Bass.

Bada, S. O. (2015). Constructivism learning theory: A paradigm for teaching and learning. Journal of Research $\mathcal{E}$ Method in Education, 6, 66-70.

Bolliger, D. U. (2004). Key factors for determining student satisfaction in online courses. International Journal on Elearning, 3, 61-67.

Bolliger, D. U., \& Wasilik, O. (2009). Factors influencing faculty satisfaction with online teaching and learning in higher education. Distance Education, 30, 103-116. https:// doi.org/10.1080/01587910902845949

Brenner, J. (2013). Pew Research Center's Internet \& American Life Project. Pew Internet: Mobile. Retrieved November 16, 2013.

Bruner, J. S. (1966). Toward a theory of instruction (Vol. 59). Cambridge, MA: Harvard University Press.

Dikkers, S. (2012). Dewey buys a smart phone. In S. Dikkers, J. Martin, \& B. Coulter (Eds.), Mobile media learning (pp. 19-26). Berlin: Springer-Verlag.

Driscoll, M., \& Van Barneveld, A. (2015). Applying learning theory to mobile learning (Vol. 32). American Society for Training \& Development.

Hassanein, K., \& Wang, F. (2010). Understanding student satisfaction in a mobile learning environment: The role of internet and external facilitators. Paper presented at the IEEE Computer Society, Canada. https://doi.org/10.1109/ICMB-GMR.2010.38

Hein, G. E. (1991). Constructivist learning theory. Retrieved from https:/ / www.exploratorium.edu/education/ifi/constructivist-learning

Ichikawa, F., Chipchase, J., \& Grignani, R. (2005). Where's the phone? A study of mobile phone location in public spaces. Paper presented at the 2005 2nd Asia Pacific Conference on Mobile Technology, Applications and Systems, Guangzhou, China.

Koszalka, T. A., \& Ntloedibe-Kuswani, G. S. (2010). Literature on the safe and disruptive learning potential of mobile technologies. Distance Education, 31, 139-157. https:// doi.org/10.1080/01587919.2010.498082

Leonard, H. (2013). There will soon be one smartphone for every five people in the world. Business Insider.

Liaw, S. (2008). Investigating students' perceived satisfaction, behavioral intention, and effectiveness of e-learning: A case study of the Blackboard system. Computers $\mathcal{E}$ Education, 51, 864-873. https:/ / doi.org/10.1016/j.compedu.2007.09.005

Lunenburg, F. C. (2011). Critical thinking and constructivism techniques for improving student achievement. National Forum of Teacher Education Journal, 21, 1-9.

McQuiggan, S., Kosturko, L., McQuiggan, J., \& Sabourin, J. (2015). Mobile technology: A handbook for developers, educators, and learners. New Jersey: Wiley.

Moses, O. O. (2008). Improving mobile learning with enhanced Shih's model of mobile learning. Online Submission, 5, 22-28.

Murphy, E. (1997). Constructivism: From philosophy to practice (Report No. 039420). Lanham, Maryland. (ED444966). Oxford English Dictionary. (2007). Oxford English dictionary online. JSTOR.

Peng, H., Su, Y. J., Chou, C., \& Tsai, C. C. (2009). Ubiquitous knowledge construction: Mobile learning re-defined and a conceptual framework. Innovations in Education and Teaching international, 46, 171-183. https:/ / doi.org/10.1080/14703290902843828

Rice, M. L., \& Wilson, E. K. (1999). How technology aids constructivism in the social studies classroom. The Social Studies, 90, 28-33. https:/ / doi.org/10.1080/00377999909602388 
Sachs, D., \& Hale, N. (2003). Pace university's focus on student satisfaction with student services in online education. Journal of Asynchronous Learning Networks, 7, 36-42.

Sarigöz, O. (2016). An examination of vocational school students' perceptions toward mobile learning. Journal of International Social Research, 9, 1485-1491. https:/ / doi.org/10.17719/jisr.20164317719

Sawang, S., Newton, C., \& Jamieson, K. (2013). Increasing learners' satisfaction/intention to adopt more e-learning. Education+ Training, 55, 83-105. https:// doi.org/10.1108/00400911311295031

Siemens, G. (2005). Connectivism: A learning theory for the digital age. International Journal of Instructional Technology \& Distance Learning. Retrieved from http:/ / www.itdl.org/journal/jan_05/article01.htm

Tan, G. W.-H., Ooi, K.-B., Sim, J.-J., \& Phusavat, K. (2012). Determinants of mobile learning adoption: An empirical analysis. Journal of Computer Information Systems, 52, 82-91.

Wali, E., Winters, N., \& Oliver, M. (2008). Maintaining, changing and crossing contexts: An activity theoretic reinterpretation of mobile learning. ALT-J, 16, 41-57. https:/ / doi.org/10.3402/rlt.v16i1.10884

Wang, M., Shen, R., Novak, D., \& Pan, X. (2009). The impact of mobile learning on students' learning behaviours and performance: Report from a large blended classroom. British Journal of Educational Technology, 40, 673695. https:/ / doi.org/10.1111/j.1467-8535.2008.00846.x

\section{http://www.ejmste.com}

